\title{
Can you teach research in 10 minutes? Embedding information literacy micro-sessions in module programmes
}

\section{Rachael Hunter}

Coventry University London

\begin{abstract}
This case study discusses the inception and continued delivery of 10-minute micro research skills sessions within two entrepreneurship modules at Coventry University London. The case study starts with an explanation of how and why the project was developed. Its rationale was underpinned by both established, current bite-sized learning research, and established psychological and neural evidence. This paper describes how these practices are used in the workplace to promote continuous professional development and disseminate company information for training purposes. Discussing both the delivery and skills content, this paper explains the methods used by the Information and Skills Development Specialist (ISDS) in each 10-minute session to engage students and embed database searching skills in to their routine study practices. It also explains how this practice has been adopted by students and how the skills have been embedded to enhance their final business pitches at the end of their modules.
\end{abstract}

Keywords: microteaching; microlearning; learning design; information literacy; skills development; research skills; transferrable skills.

\section{Background}

Study skills at Coventry University London have undergone a decade of delivery evolution. Starting as mandatory modules delivered by academic staff, they were 'bolted-on' to the main study programmes to provide students with the opportunity to develop the core research and analytical skills that they would need to complete their courses to a high standard. However, as Wingate (2006) argues, bolting the skills on, rather than embedding them in, is ineffectual; rather like trying to add flour to a cake after it has been baked. 
Taking this into consideration, and following the removal of the core skills modules for postgraduate students, there was a shift towards utilising the skills of librarians and academics to co-design and co-deliver a more embedded approach. Embedded sessions at Coventry University London are one-hour workshops designed to provide information literacy skills, tailored to particular student assessment. Usually delivered in weeks 3 and 4 of a module by the ISDS or the Assistant Librarian, they provide a platform for students to develop transferrable skills in research, referencing, critical thinking, and academic writing. Whilst still largely successful, this one-step approach, despite being tailored to particular academic needs, has sometimes proved problematic for students as they continue through the course. These workshops have not always allowed space for the fundamental development of these skills to be successfully transferred as students still displayed a silo mentality. In this context, silo mentalities refer to the lack of knowledge transfer in their assessments; the databases that students access to answer one assessment in the module were traditionally not used to access information for the next. Neither are embedded sessions a 'one size fits all' concept. It was clear that a new approach was needed. This was particularly evident in the research skills development opportunities for two entrepreneurship modules, Entrepreneurship: Creating a Business Opportunity (M059) and Entrepreneurship: Developing the Business Plan (M060). These modules are delivered in terms two and three respectively, as part of a one-year Master of Business Administration (MBA) programme.

\section{The rationale}

The project was born out of three distinct needs:

1. The effectiveness of embedded delivery in the M059/M060 modules

2. The disintegration of silo mentalities

3. The validity of sources used in assessment

As previous embedded delivery models had not proved entirely successful in these modules, a microteaching approach was considered as an alternative. Microteaching and microlearning are not new concepts. Since the introduction of microteaching by Stanford 
University in the 1960s, evidence of its efficacy in professional development has been noted (Van Monfrands, 1969; Cooper \& Allen, 1970; Minton, 1997, cited in Higgins and Nicholl, 2003). Whilst most of these papers highlight a need for further research before definite conclusions can be drawn, they nonetheless note a level of positivity in the effectiveness of the approach. Used in workplaces for many years as a training model, it is becoming increasingly popular in higher education (Gordon, 1997; Armstrong and SadlerSmith, 2008; Emerson and Berge, 2018). From a microlearning perspective, psychological and neuro-scientific evidence (Cooper, 1990, p.2; Perry, 2000, p.34; Dwyer, 2002) highlights that the brain's cognitive load can be reduced through necessary breaks in information processing to stem neural system fatigue. Recent research confirms this view, suggesting that regular bite-sized sessions can help individuals process information and learn more effectively (Benton-Kupper, 2001; Gutierrez Trejos, 2016; Mella, 2016; Alqurashi 2017; Melvin 2017). For information literacy development, this approach can be beneficial as it allows for the scaffolding of concepts in practice, as evidenced in this adapted form of Baumgartner's (2013, p.6) 'Competence Spiral' as a design model. First, the principles of research would be established, students would apply this knowledge to their particular businesses, and communicate this in their assessment.

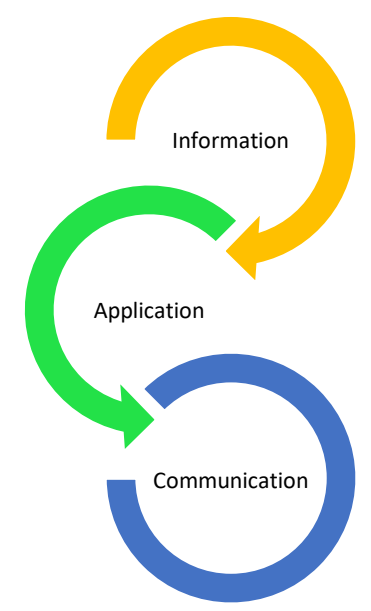

(Adapted from Baumgartner, 2013, p.6)

Silo mentalities are generally attributed to organisations and in particular, departments that deprive information access to other departments (Mohapeloa, 2017). However, as Paige et al. (2017) assert, the same mentality can be observed in students. Anecdotal evidence collected from Coventry University London students since this project began concurs with 
this view, and, as previously mentioned, notes that several learners do not utilise the same resource sources for different assessments, both within this module, and across their course. Feedback can also be viewed in isolation and not considered as a developmental opportunity; it is monologic, rather than dialogic (Carless, 2013). To help break down these mentalities, the 10-minute sessions would include consistent reference to how the information gathered in each session could be conjoined, like the pieces of a jigsaw, to form an overall conclusion. As the M059 students progressed to M060, the same databases would be demonstrated in relation to a different topic, thus acknowledging a further development of transferrable skills and optimistically allowing for additional destruction of the silo mentality.

The validity of the sources used for assessments was a cause for concern. Statistical data from the Library shows an increase in the delivery of more traditional one-hour embedded sessions for finding and evaluating information, rising from 28 in the 2017/18 academic year, to 61 in 2018/19 academic year, and to 63 in the 2019/20 academic year. These figures do not include the 10-minute microlearning workshops (see figure1).

\section{Figure 1. Research skills embedded sessions requests.}

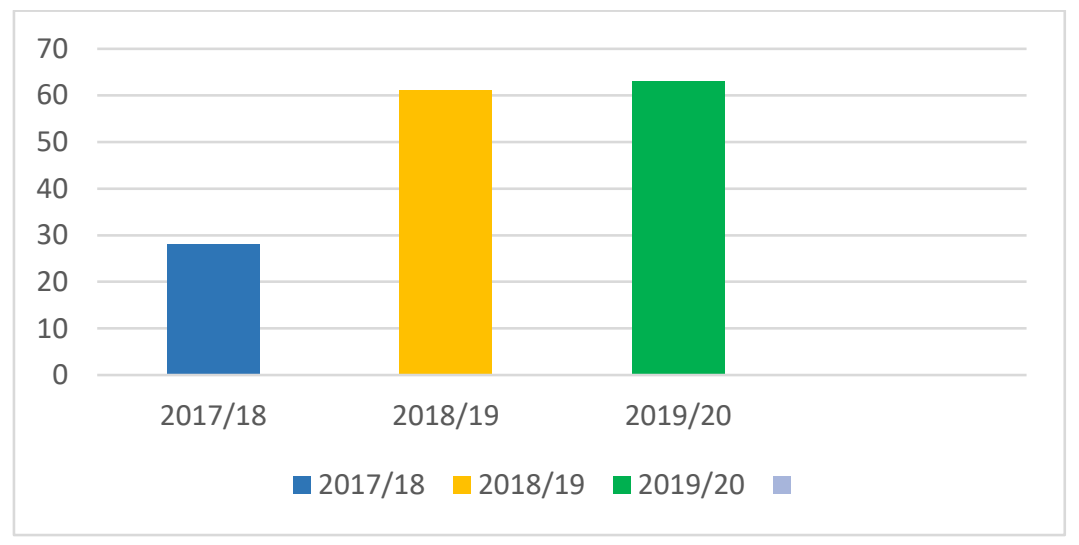

All of these were arranged between academics and the ISDS, as academics noted a reliance on Google over academic sources such as textbooks and journal articles. This was not behaviour restricted to this institution; evidence of this reliance has been documented previously by Judd and Kennedy (2011), who observed that students' confidence in information provided by Google and Wikipedia was high, and the usage of the library service to gather peer-reviewed, validated information was low. It was hoped 
that this project would further promote the importance and availability of these peerreviewed resources to encourage students to engage in more critical research practices.

\section{The project}

Following a request from a course director to deliver a 10-minute embedded research session at the start of a lecture, a strategy was co-developed between the module leader and the ISDS for two entrepreneurship modules, M059 and M060. Research is currently the only area to adopt this 10-minute approach. All other areas of skills development (referencing, critical thinking, avoiding plagiarism) are delivered as one-hour embedded sessions. This collaboration was key; for the project to have any notable impact, students needed to be aware that these research skills sessions had the full endorsement of the module leader, as they had the detailed understanding of the assessment in relation to the skills development. Without this correlation, it was probable that students would display indifference and an absence of comprehension as to the relevance of this information to their assessment (Bloxham and Boyd 2007).

Six workshops were developed as a trial run for the September 2017/2018 cohort, with delivery taking place in early 2018. Each workshop focussed on a particular database and delivered training on both its usage and its usefulness for module assessment. For M059, this was the UK restaurant industry, for M060, it was business operations and strategies for any industry. Each session included an explanation and demonstration of a particular search technique: Boolean searching, filters, pearl growing, truncation, and keyword searching. The databases chosen were: Euromonitor Passport, Mintel, and IBISWorld, along with the website for the UK Government's statistics producer, Office for National Statistics (ONS). This Government data was used to determine average family spending and how this may affect the profits of the students' hypothetical businesses. The initial session provided instruction on the use of Google Scholar, along with an introduction to research. The final session would recap on the learning. 150 students took part in this initial trial. 
Given the large numbers of students, and the need for engagement and interactivity, it was decided that a live demonstration, driven by student questions and linked to module assessment would be the best method of delivery. The ISDS elected not to disparage Google in these sessions, providing as it did a fundamental starting point for most students to start their research that was both comfortable and familiar. The introductory session would, instead, be focussed towards linking Google Scholar to Locate, Coventry University London's Library catalogue, to enable students' access to valid sources via accustomed means.

Students' learning journeys are individual and non-linear, so the microlearning sessions were designed to be reflective of this, offering the fundamental mechanics of database searching along with guidance on their application. Resources were made available via the Library and course pages on Moodle, and the students had ample opportunity to follow up with the librarian after the sessions. Following this initial trial, feedback was collected from students through an informal class survey conducted by the module leader. Student feedback was generally positive, with the module leader stating: "[The] 10mins pitches [....] on how to research were: understandable; acted upon; useful to the students and to the teachers, and should be introduced in all lectures" (Morrison, 2018).

At the end of the trial, all student pitches referred to information taken from the taught databases. Whilst this showed evidence of the initial impact, and allowed for the continuation of the programme for future cohorts, it became clear in the final pitches that the data taken from these reports was not used in direct relation to the students' hypothetical businesses. They used the information simply because they were told that they should; not because they were aware of how the data collected may impact these businesses. In short, they stated the 'what', without considering the 'why?'.

This realisation led to a change in delivery for the January 2018/19 cohort with the introduction of the REVIEW framework (City and Islington College, 2016). Adapted from Blakeslee's (2004) CRAAP test, this framework sought to engender critical thinking proficiency through the evaluation of an article's Relevance, Expertise, Viewpoint, Intended audience, Evidence and When published data in relation to their business pitches. Establishing how these database platforms worked sought to develop 
understanding of a concept in practice, and stimulate transferrable skill development. It was hoped that teaching this in conjunction with established search techniques mentioned previously would help to focus research and reduce searching time as less time would be spent reading material that was irrelevant to their assessment. Anecdotal evidence from the author and academics confirms that this approach reduces the time spent on their research.

The programme's evolution since January 2018 has been forged through continual evaluation and collaboration with the module leader. This has seen, in addition to the REVIEW framework, two new platforms added to the programme: the database Statista and the UK Government directory, Companies House. These respectively provided students with a global platform with which to see the data in wider context, and allow for close examination of particular UK businesses through their annual reports. The data could then be analysed in relation to the students' own hypothetical businesses. Recent research on current microlearning practices from Chuang (2019) and Buhu and Buhu (2019) has shaped the present asynchronous delivery model used since the pandemic through the recommendation of technologies to package the learning effectively.

\section{The impact}

The ISDS was invited to the final pitch presentations at the end of the modules. This was beneficial for the ISDS to see the application of the data within the presentation and assess the validity of data sources. It also helped to highlight the cross-department collaboration.

Tracing the development of this project from its first inception for the September 2017/18 cohort to the present, the following impacts have been noted through this observation of the student's pitches at the end of the module. Students' showed:

- Increased citations from reliable sources; greater reference had been made to these sources throughout the pitch 
- Stronger connections between sources for cogent conclusions. Students now showed that they could use this data in relation to their hypothetical businesses, and detail any potential effects

- Improved critical thinking skills, evidenced though the aforementioned connections between sources

- An increase in grade averages across the three intakes, as evidenced below

Recent data taken from the registry team at Coventry University London in July 2020 showed a slight increase in the average grades for the business pitch assessment, rising from $61.4 \%$ in $2018 / 19$ to $62.3 \%$ in $2019 / 20$ for M059 across all three intakes. The M060 course showed a similar raise in grades from $60.5 \%$ in $2018 / 19$ to $62.8 \%$ in $2019 / 20$, again across all cohorts. When compared with the $2017 / 18$ grade average of $57.3 \%$ for M059 and $60 \%$ for $\mathrm{M} 060$, an overall percentage increase of $5 \%$ and $2.8 \%$ respectively is noted. Whilst this impact cannot wholly be attributed to the 10-minute tutorials, it is nonetheless notable (see figure 2).

Figure 2. Increase in grade averages in each module

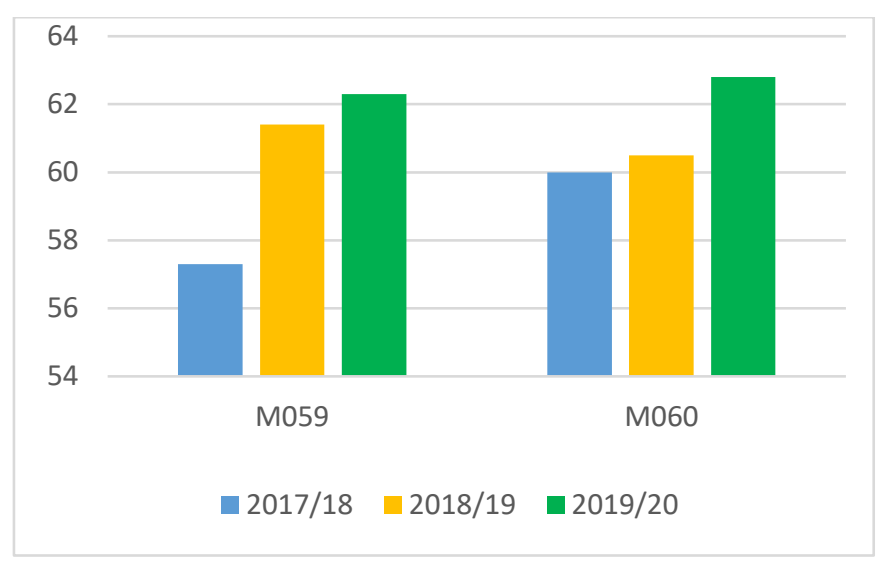

The following was also observed through informal and Modular Evaluation Questionnaires (MEQ) feedback, and statistical data:

- Increased communication with the ISDS through 1-1 appointments. The Library's statistics report shows that 1-1 tutorials specific to finding information rose from 17 in 2018/19, to 40 in 2019/20. An increase of 135\% (see figure 3) 
- Increased recognition and appreciation of the Library and Learning Innovation department and its role within the institution. Statistical data from the library guide webpages showed in increase in online traffic from 54,653 hits in $2018 / 19$ to 67,571 hits in 2019/20. An increase of $23.6 \%$ (see figure 4 )

Figure 3. Increase in 1-1 finding information requests

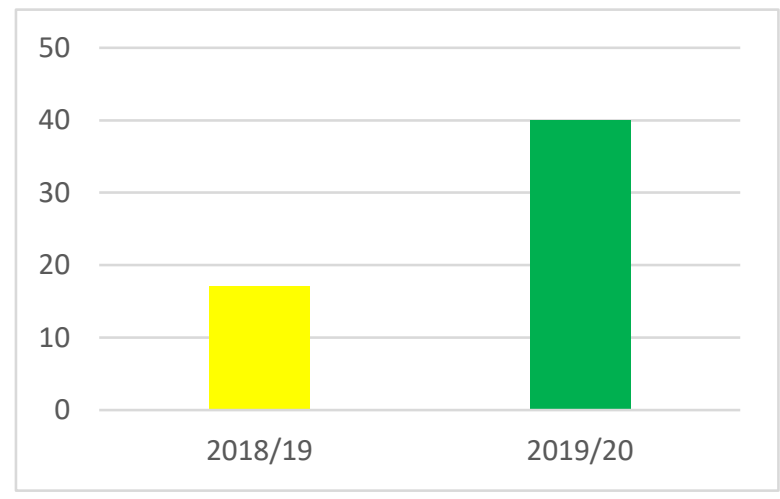

Figure 4: Increase in Library guides webpage hits

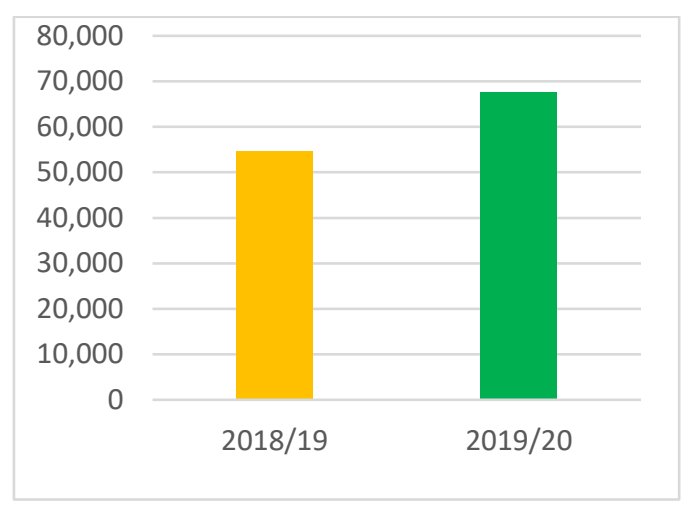

Also in evidence is the wider acknowledgement of the project in other faculties, leading to the development of similar workshops for both undergraduate (363LON Fashion Management) and additional postgraduate (M003 Marketing in a Global Age) modules. Data has not been collected from these modules to ascertain its impact on grades from one academic year to the next, but students demonstrated increased awareness of the databases through their questions and comments during the workshops. Increased engagement with the ISDS was also noted through the previously mentioned rise in 1-1 requests and site traffic. 


\section{COVID-19}

Each cohort has brought new challenges and allowed for a consistent evolution of the project. The Covid-19 pandemic in particular brought with it its own specific challenges and identified the need for further delivery diversity. The original project was delivered synchronously, with the option of further asynchronous content if the student wished to access it. Whilst this delivery mode was still possible, time zones, technological issues and alternative working practices dictated that a new method was needed. Aforementioned research on contemporary microlearning methods from Chuang (2019) and Buhu and Buhu (2019) informed this delivery model as the ISDS took the decision to create a series of eight '10-minute tutorials' over the traditional synchronous delivery mode. Containing entirely asynchronous content, each tutorial focuses on a particular database and takes the students through the research process via presentation and video demonstration. This is then promoted through the Moodle pages for each module, where student engagement can be tracked. There is currently no available data to determine whether this approach will affect the average grades for these modules, or how the students will respond to the change in format. Students are still able to seek additional support from the ISDS through Microsoft Teams chat, email and live question and answer (Q\&A) sessions.

\section{Conclusions}

Secondary research has shown that microlearning has benefits for cognitive processing as the brain has opportunity and time to absorb the information (Cooper, 1990, p.2; Dwyer, 2002; Perry, 2000, p.34). This can be utilised in a higher education setting just as effectively as in the workplace. This, along with evidence undertaken from primary research, has shown that this project has garnered an increased awareness of both valid research practices and the Library and Learning Innovation service. Collaboration between the ISDS and the module leader was fundamental to the project's development. Without this, students would have no context for their skills development and be disinclined to learn these skills. Despite the small, if positive, impact on average grades since 2018, the project has highlighted a demonstrable effect on student pitches at the end of their modules. Students are now citing data from these platforms and examining the 
relationship between this and their businesses. The inclusion of this microlearning project within other modules in 2019 (363LON and M003) establishes the project's flexible and tailored design. This has allowed for its continued evolution and made it suitable for all. Given this evidence, it is hoped that this model could be adopted by other faculties to facilitate information literacy practice and its continual development to students.

\section{Acknowledgements}

The author would like to acknowledge the support of Callum Morrison and the Library and Learning Innovation department at Coventry University London in developing the project.

\section{References}

Alqurashi, E. (2017) 'Microlearning: a pedagogical approach for technology integration'. International Educational Technology Conference. Harvard, Cambridge, MA. August 2017. Available at:

https://www.researchgate.net/publication/319715909 Microlearning A Pedagogical Approach For Technology Integration (Accessed: 5 August 2020).

Armstrong, S., \& Sadler-Smith, E. (2008) 'Learning on demand, at your own pace, in rapid bite-sized chunks: the future shape of management development?' Academy of Management Learning \& Education, 7(4), pp.571-586 Available at: https://www.jstor.org/stable/27759160 (Accessed: 7 August 2020).

Baumgartner, P. (2013) Educational dimensions of microlearning - towards a taxonomy for microlearning. Available at: https://imb.donau-uni.ac.at/themetest/wpcontent/uploads/2013/04/Baumgartner 2013 Educational-Dimensions-forMicroLearning.pdf (Accessed: 1 August 2020).

Benton-Kupper, J. (2001) 'The microteaching experience: student perspectives', Education 121(4), pp. 830-836. 
Blakeslee, S. (2004) 'The CRAAP test', LOEX Quarterly, 31(3), 6-7. Available at https://commons.emich.edu/cgi/viewcontent.cgi?article=1009\&context=loexquarterly (Accessed: 7 August 2020).

Bloxham, S., and Boyd, P. (2007) Developing effective assessment in higher education: a practical guide. London: McGraw-Hill.

Buhu, A. and Buhu, L. (2019) 'The applications of microlearning in higher education in textiles' The 15th International Scientific Conference eLearning and Software for Education. Bucharest, April 11-12, 2019 Available at: DOI:10.12753/2066-026X-19189 (Accessed: 7 August 2020).

Carless, D. (2013) 'Sustainable feedback and the development of student self-evaluative capacities', pp.113-22, in Merry, S., Price, M., Carless, D. and Taras, M. (eds.) Reconceptualising feedback in higher education: developing dialogue with students London: Taylor and Francis.

Chuang, P.M. (2019) 'New training programme offers bite-sized learning for busy SME bosses: modules cover areas such as leadership thinking and are 'stackable' so learners can earn higher certification' The Business Times. Available at: https://www.businesstimes.com.sg/government-economy/new-training-programmeoffers-bite-sized-learning-for-busy-sme-bosses (Accessed: 7 August 2020).

City and Islington College (2016) Finding and using information in the $21^{\text {st }}$ century: a digital information literacy skills builder. [Unpublished policy document].

Cooper, G. (1990) 'Cognitive load theory as an aid for instructional design', Australasian Journal of Educational Technology 6(2), pp.108-113 Available at: https://doi.org/10.14742/ajet.2322 (Accessed 30th September 2020).

Cooper, J.M \& Allen, D.W. (1970) Microteaching: history and present status. Available at: https://eric.ed.gov/?id=ED036471 (Accessed: 30 September 2020).

Dwyer, B.M. (2002) 'Training strategies for the twenty-first century: using recent research on learning to enhance training', Innovations in Education and Teaching 
International 39(4), pp.265-270 Available at:

https://doi.org/10.1080/13558000210161115 (Accessed: 10 August 2020).

Emerson, L. C., \& Berge, Z. L. (2018). 'Microlearning: knowledge management applications and competency-based training in the workplace', Knowledge Management \& E-Learning, 10(2), pp.125-132. Available at: http://www.kmeljournal.org/ojs/index.php/online-publication/article/view/17/17 (Accessed: 10 August 2020).

Gordon, J. (1997) 'Infonuggets: The bite-sized future of corporate training?' Training, 34(7), pp.26-33.

Guttierrez Trejos, K. (2016) 'Learning: think small: 8 commandments of bitesized learning', Technology Enabled Learning Excellence Essentials. Available at: https://www.hr.com/en/magazines/all articles/learning-think-small-8commandments-of-bite-sized- ije1fm54.html (Accessed 30 September 2020).

Higgins, A. \& Nicholl, H. (2003) 'The experiences of lecturers and students in the use of microteaching as a teaching strategy', Nurse Education in Practice 3(4), pp.220227. Available at: https://doi.org/10.1016/S1471-5953(02)00106-3 (Accessed: 30 September 2020).

Judd, T. \& Kennedy, G. (2011). 'Expediency-based practice? medical students' reliance on Google and Wikipedia for biomedical inquiries', British Journal of Educational Technology, 42(2), pp.351-360 Available at: https://doi.org/10.1111/j.14678535.2009.01019.x (Accessed: 10 August 2020).

Mella, M. (2016) 'Taking micro-learning beyond bite-sized: a few tips for creating a rounded experience', Technology Enabled Learning Excellence Essentials. Available at:

https://www.hr.com/en/magazines/training development excellence essentials/ma y 2016 technology enabled learning/taking-micro-learning-beyond-bite-sized-afew-tips inu149to.html (Accessed 30 September 2020). 
Melvin, C. (2017) 'Employee learning: bite-sized is the right size: tips to transform information into big successes', Technology Enabled Learning Excellence Essentials Available at: https://www.hr.com/en/magazines/all articles/employeelearning-bite-sized-is-the-right-size-tip j8dzr1c8.html (Accessed 30 September 2020).

Mohapeloa, T. (2017). Effects of silo mentality on corporate ITC's business model. Proceedings of the International Conference on Business Excellence, 11(1), pp.1009-1019. Available at: https://doi.org/10.1515/picbe-2017-0105 (Accessed: 10 August 2020).

Morrison, C . (2018) 10mins 'how to research' pitches to M059 were understandable, acted upon by students [email].

Paige, J.T., Garbee, D.D., Yu, Q. \& Rusnak, V. 2017, 'Team training of inter-professional students (TTIPS) for improving teamwork', BMJ Simulation \& Technology Enhanced Learning 3(4), pp. 127. Available at: DOl:10.1136/bmjstel-2017-000194 (Accessed: 10 August 2020).

Perry, B. (2000) 'How the brain learns best', Instructor, 110(4), pp.34-35. Available at: https://www.scholastic.com/teachers/articles/teaching-content/how-brain-learnsbest/ (Accessed: 10 August 2020).

Van Mondfrans, A.P (1969) 'Student attitudes and achievement in an educational psychology course after micro-teaching', Educational Psychologist, 6(2), pp.15-17. Available at: https://doi.org/10.1080/00461526909528978 (Accessed: 30 September 2020).

Wingate, U. (2006) 'Doing away with 'study skills”, Teaching in Higher Education, 11(4), pp.457-469. Available at: https://doi.org/10.1080/13562510600874268 (Accessed: 10 August 2020).

\section{Author details}


Rachael Hunter is the Information and Skills Development Specialist at Coventry University London. She has worked in further and higher education, and has a special interest in embedding skills development in course and lesson design. 